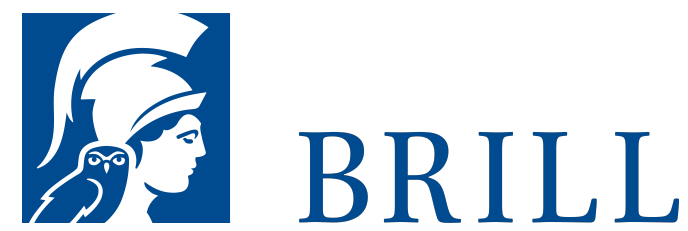

\title{
Dimensionen der Fiktionalität
}

Analyse eines Grundbegriffs der Literaturwissenschaft

Author: Eva-Maria Konrad

Im Zentrum der Untersuchung steht die Klärung des für viele literaturtheoretische Arbeiten zentralen, häufig aber nicht ausreichend reflektierten Begriffs der Fiktionalität. Der Fülle der bereits vorhandenen Fiktionalitätstheorien wird dabei zunächst mit der Einführung eines Drei-Ebenen-Modells begegnet. Dieses ermöglicht eine Kategorisierung und Systematisierung nach den folgenden Aspekten: Welches Kriterium ist für die Differenzierung zwischen fiktionalen und faktualen Texten maßgeblich? Welche Instanz entscheidet über die Fiktionalität bzw. Faktualität eines Textes? Und als wie umfassend gilt die Fiktionalität literarischer Texte? Auf dieser Grundlage profiliert das Buch mit dem Panfiktionalismus, Autonomismus und Kompositionalismus drei konkurrierende Theorien zur Reichweite der Fiktionalität. Die kritische Analyse widmet sich dabei nicht nur den vorhandenen Definitionen und Befürwortern, sondern diskutiert auch die spezifischen Vor- und Nachteile der jeweiligen Positionen. Unter Entwicklung einer umfassenden Definition des Kompositionalismus wird schließlich für diejenige Theorie plädiert, die fiktionale Texte als eine Mischung aus fiktionalen und faktualen Elementen begreift.

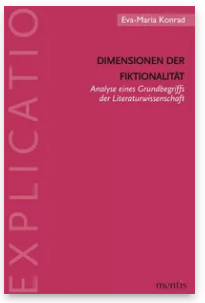

Pages: 500

Seiten

Language:

German

Subjects:

General,

Literature and

Cultural Studies

Publisher: Brill | mentis

Series:

Explicatio

E-Book (PDF)

Released online:

o1 Oct 2014

ISBN: 978-3-

89785-642-4

List price

Paperback

Publication date:

o1 Oct 2014

ISBN: 978-3-

89785-845-9

List price 
For more information see brill.com

Order information: Order online at brill.com +44330 333 0049 | customerservices@brill.com Submission information: brill.com/authors

Titles published by Brill | Fink, Brill | mentis or Brill | Schöningh: +49(o)715413279216| brill@brocom.de 